\title{
A microRNA-125a variant, which affects its mature processing, increases the risk of radiation-induced pneumonitis in patients with non-small-cell lung cancer
}

\author{
HONG-YAN QUAN $^{1}$, TIAN YUAN ${ }^{1}$ and JIAN-FENG HAO ${ }^{2}$ \\ ${ }^{1}$ Oncology Department; ${ }^{2}$ Biological Center, Shaanxi Friendship Hospital, Xi'an, Shaanxi 710008, P.R. China
}

Received September 15, 2015; Accepted August 25, 2016

DOI: $10.3892 / \mathrm{mmr} .2018 .9406$

\begin{abstract}
The present study aimed to investigate the role of microRNA (miR)-125a in the development of pneumonitis inpatients with non-small-cell lung cancer that received radiotherapy. In addition, the study aimed to determine how the miR-125a affects its target, transforming growth factor $\beta$ $(T G F \beta)$. Bioinformatics tools were used to identify a potential miR-125a binding site in the 3'untranslated region of $T G F \beta$, which was subsequently confirmed using a dual-luciferase reporter system. In addition, tissue samples were collected from patients with lung cancer and genotyped as CC $(n=36)$, $\mathrm{CT}(\mathrm{n}=28)$ or TT $(\mathrm{n}=6)$. The expression levels of miR-125a and $T G F \beta$ in these samples were determined, and CC genotype samples demonstrated upregulated miR-125a expression, and downregulated TGF $\beta$ protein and mRNA expression compared with samples carrying the minor allele, T. To further investigate the association between the rs12976445 polymorphism and the risk of pneumonitis in patients with lung cancer that received radiotherapy, 534 lung cancer patients diagnosed with pneumonitis and 489lung cancer patients without pneumonitis were recruited. rs12976445 was shown to be significantly associated with the risk of pneumonitis. In conclusion, the rs12976445 polymorphism increased expression levels of TGF $\beta$ by decreasing the expression of miR-125a, and therefore may be associated with the development of pneumonitis in patients with lung cancer that receive radiotherapy.
\end{abstract}

\section{Introduction}

Lung cancer is the leading cause of cancer-associated mortality, with 1 million patients worldwide each year succumbing to this disease (1). The majority of lung cancer cases $(>80 \%)$ are non-small cell lung cancer (NSCLC), which consists of large

Correspondence to: Dr Jian-Feng Hao, Biological Center, Shaanxi Friendship Hospital, 277 W Youyi Road, Xi'an, Shaanxi 710008, P.R. China

E-mail: oncoradiation@163.com

Key words: rs12976445, polymorphism, miR-125a, transforming growth factor $\beta$, pneumonitis, non-small-cell lung cancer cell carcinoma, adenocarcinoma and squamous cell carcinoma. However, $\sim 30 \%$ of patients with NSCLC do not receive a specific classification (2,3). A standard treatment approach for patients with unresectable NSCLC is radiotherapy alone or combined with chemotherapy, as this may improve overall survival and control or reduce the lesion site, and prevent metastases (4). It has been reported that radiation-induced pneumonitis in patients with NSCLC is correlated with numerous factors (5). The most extensively investigated factors include dose-volume parameters to healthy lung tissue and selected cytokines (6); however, thus far none have been demonstrated to be accurate enough to control the radiation dose to prevent further damage. In addition, it is difficult to balance the requirement for high-dose radiation to achieve adequate tumor control with the need to limit the dose to healthy lung tissue in patients with larger tumors (7). A previous study demonstrated that inflammatory and fibrogenic cytokines are critical in the development of pneumonitis as a complication of radiotherapy (8). Inflammation may be regulated by transforming growth factor $\beta(T G F \beta)$, a pleiotropic cytokine that stimulates connective tissue collagen formation and reduces degradation, thus resulting in fibrosis (9). TGF $\beta$ has been revealed to be markedly associated with damage to the lung architecture (8). Previous studies have identified TGF $\beta$ as a marker of patients at risk of developing symptomatic pneumonitis $(10,11)$.

In the majority of cells, differentiation, proliferation and other functions are controlled by the TGF $\beta 1$ gene. Numerous cellular processes in the developing embryo and the adult organism, including homeostasis, apoptosis, differentiation and growth are associated with the TGF $\beta 1$ signaling pathway (12). As an important modulator of the inflammatory response, TGF $\beta$ has been extensively investigated in the irradiation-induced development of tissue fibrosis (13). Plasma levels of TGF $\beta 1$ have been investigated as a predictor for lung injury induced by radiotherapy. Human and animal studies have indicated that TGF $\beta$ acts as primary regulator in the process of lung injury induced by radiation $(7,14,15)$. Following administration of anti-TGF $\beta$ antibodies, TGF $\beta$ activation was reduced and the inflammatory response decreased several weeks after radiotherapy, further demonstrating that targeting the TGF $\beta$ signaling pathway may be a potential strategy to prevent lung injury induced by radiotherapy (16).

MicroRNAs (miRNAs) are endogenously encoded single-stranded RNAs 22 nucleotides in length, which are 
essential in various pathological conditions (17). miRNAs bind specifically to target messenger RNAs (mRNAs) and induce mRNA degradation or translational repression, resulting in posttranscriptional gene suppression (18). Various biological processes, including immunity, inflammation, cellular development, apoptosis, metabolism, differentiation and proliferation are regulated by miRNAs (17-19). However, a single nucleotide polymorphism (SNP; rs12976445) in pre-microRNA-125a may compromise the mature processing of the miRNA, reducing miR-125a production (20). Therefore, it has been hypothesized that rs12976445 may be associated with the risk of developing pneumonitis in patients with NSCLC treated with radiotherapy, by affecting the production of miR-125a, and consequently its target, $T G F \beta$ expression.

\section{Materials and methods}

Ethical considerations. The present study was conducted according to the Declaration of Helsinki guidelines and the study protocol was approved by the Human Ethics Committee of Shaanxi Friendship Hospital (Xi'an, China). Written informed consent was obtained from all participants prior to the study.

Patient eligibility and study design. The present study was performed on patients with NSCLC $(n=1,023)$ who were admitted to the Oncology Department, Shaanxi Friendship Hospital. All patients received chest computed tomography (CT), pulmonary function tests, biochemical analysis, a complete blood count and a physical examination, and a complete medical history was taken (Table I). The patients were recorded and treated in accordance with the Radiation Therapy Oncology Group and the European Organization for the Research and Treatment of Cancer guidelines. All patients were followed up; assessments included chest CT, chest X-ray and a physical examination. Assessments were performed at three-month intervals for a period of two years following the completion of radiotherapy, and subsequently at six-month intervals. Patients were divided into two groups based on the presence or absence of pneumonitis (pneumonitis positive, $\mathrm{n}=534$; pneumonitis negative, $\mathrm{n}=489$ ). The criteria for enrollment in the present study included: i) A diagnosis of NSCLC; ii) no history of surgery and chemotherapy; iii) good heart, liver and kidney function; iv) no distant metastasis; v) no history of myocardial infarction, cerebral infarction or other critical illness in the previous six months; vi) a life expectancy of at least six months; and vii) a prescribed radiation dose of 50-70 Gy. Patients with any of the following were excluded: i) A history of surgery or chemotherapy for a thoracic tumor; ii) a history of severe pulmonary dysfunction or pulmonary fibrosis; iii) a history of total or partial pulmonary lobectomy; iv) poor general health; v) intolerance to radiation or incomplete radiotherapy; vi) a diagnosis of asthma, serious chronic bronchitis, emphysema or severe pulmonary infection; and vii) a diagnosis of another serious disease, including myocardial infarction and cerebral infarction within the previous six months. Lung tissue samples (70) were obtained from 1,023 NSCLC patients: [CC $=36,18$ pneumonitis $(+), 18$, pneumonitis (-); CT=28, 14 pneumonitis (+), 14 pneumonitis (-); TT=6, 3 pneumonitis (+), 3 pneumonitis (-)] and genotyping for rs12976445 was conducted on blood samples obtained from all patients.

Genotyping. The QIAamp DNA Blood Mini kit (Qiagen, Inc., Valencia, CA, USA) was used to extract genomic DNA from blood $(200 \mu \mathrm{l})$ samples, according to the manufacturer's protocol. Sanger sequencing using an ABI PRISM ${ }^{\circledR} 3100$ Genetic Analyzer (Applied Biosystems; Thermo Fisher Scientific, Inc., Waltham, MA, USA) was performed to determine the genotype of rs12976445.

Cell culture and transfection. A549 human lung carcinoma cells were obtained from the American Type Culture Collection (Manassas, VA, USA), and were cultured in Dulbecco's modified Eagle's medium (Gibco; Thermo Fisher Scientific, Inc.) supplemented with $100 \mathrm{mg} / \mathrm{ml}$ streptomycin, $100 \mathrm{U} / \mathrm{ml}$ penicillin and $10 \%$ fetal bovine serum (Gibco; Thermo Fisher Scientific, Inc.) at $37^{\circ} \mathrm{C}$ in a $5 \% \mathrm{CO}_{2}$ atmosphere. Lipofectamine ${ }^{\circledR} 2000$ (Invitrogen; Thermo Fisher Scientific, Inc.) was used to perform transient cell transfections of small RNAs or plasmids. miR-125a mimic/antagomir (5'-CTATGTTTGAATGAGGCTTCAG-3' and 5'-CGCGTC GCCGCGTGTTTAAACG-3'; Sangon Biotech Co., Ltd., China) or $T G F \beta$ small interfering (si)RNA (5'-CCCAGA ACCAGGAGAAGAA-3' and 5'-UUCUUCUCCUGGUUC UGGG-3'; Sangon Biotech Co., Ltd., China) were transfected at a final concentration of $100 \mathrm{nM}$. Briefly, the concentration of pcDNA3 was $16 \mu \mathrm{g} / \mathrm{ml}$, the number of cells $2.0 \times 10^{5} / \mathrm{ml}$ and the duration and temperature of the transfection was $6 \mathrm{~h}$ at $37^{\circ} \mathrm{C}$. A scramble control oligo sequence with no known target in the human genome (5'-TGCACAATTTGATGC CGGTTTAGTAT-3' and 5'-TTAAAATGCAGATGCTGA ACTGGGAA-3'; Invitrogen; Thermo Fisher Scientific, Inc.) served as a control.

Plasmid construction, target prediction and luciferase assay. By scanning target gene prediction databases (www.targetscan. org), the putative target gene of the miR-125a were pooled from 3 databases. Experimental validation on miR-125a and TGF $\beta$ was performed. The full-length cDNA of the human TGF $\beta$ gene was amplified by polymerase chain reaction (PCR) and was subcloned into a pcDNA3 vector (Invitrogen; Thermo Fisher Scientific, Inc.) using the following cloning primer: Forward, 5-ATGCCGCCCTCCGGGCTGCGGCTG CTG-3' and reverse, 5'-TCAGCTGCACTTGCAGGAGCGCA -3 ' (Sangon Biotech Co., Ltd., Shanghai, China). The following primers were used to build the $T G F \beta$ 3'untranslated region (UTR) reporter plasmids (psiCHECK; Promega Corporation, Madison, WI, USA): Forward, 5'-GGTCCCGCCCCGCCC CGCCCCGCCCCG-3' and reverse, 5'-GGCCTGAACTAC TATCTTTTA-3'. The predicted binding sequence (www. mirdb.org) was mutated using QuikChange XL Site-Directed Mutagenesis kit (Stratagene; Agilent Technologies, Inc., Santa Clara, CA, USA). A549 cells were seeded onto 6-well plates at a density of $5 \times 10^{5}$. Following transfection for $48 \mathrm{~h}$, cells were lysed to determine reporter gene activity with the Dual-Luciferase ${ }^{\circledR}$ Reporter assay system (Promega Corporation, Madison, WI, USA), by measuring the proportion of Renilla plasmid vs. firefly plasmid (10:1). All experiments were performed in triplicate. 
Table I. Demographic and clinicopathological features of the participants of the present study.

\begin{tabular}{lcc}
\hline Parameter & Pneumonitis (+) & Pneumonitis (-) \\
\hline Number & 534 & 489 \\
Sex (M:F) & $534(276: 258)$ & $489(254: 235)$ \\
Average age (years) & $52.63 \pm 8.63$ & $51.37 \pm 9.33$ \\
Hypertension (\%) & 4.28 & 7.87 \\
Current smokers (\%) & 12.14 & 2.86 \\
Hyperlipidemia (\%) & 2.04 & 9.36 \\
Diabetes mellitus (\%) & 2.34 & 1.27 \\
Coronary heart disease (\%) & 7.68 & 6.12 \\
Body mass index (kg/m $\left.{ }^{2}\right)$ & $20.25 \pm 1.41$ & $21.03 \pm 0.97$ \\
\hline
\end{tabular}

M, male; F, female; Data expressed as mean \pm standard deviation.

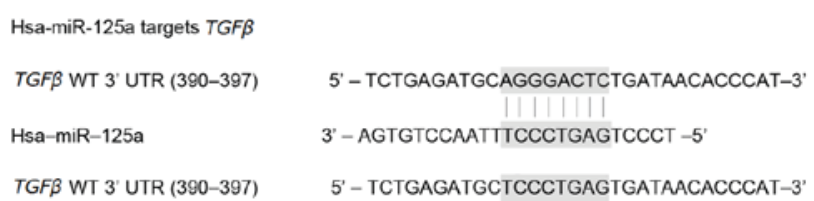

Figure 1. TGF $\beta$ was identified as a target gene of miR-125a, with the 'seed sequence' (390-397 bp) in the 3'UTR of TGF 3 . TGF $\beta$, transforming growth factor $\beta$; miR, microRNA; UTR, untranslated region; WT, wild type.

Western blot analysis. Cells were collected and lysed in radio immunoprecipitation assay buffer $[1 \mathrm{mM}$ phenylmethylsulfonyl fluoride, $0.1 \%$ sodium dodecyl sulfate (SDS), $1 \%$ sodium deoxycholate, $1 \%$ NP-40, $10 \%$ glycerol, $1 \mathrm{mM}$ dithiothreitol, $150 \mathrm{mM} \mathrm{NaCl}$ and $50 \mathrm{mM}$ Tris- $\mathrm{HCl}(\mathrm{pH} \mathrm{8.0)}$ ]. Cell lysates were cleared of cell debris by centrifugation at $20,800 \mathrm{x} \mathrm{g}$ for $15 \mathrm{~min}$ at $4^{\circ} \mathrm{C}$. The proteins were extracted using a BCA Protein Assay kit and the concentration was determined by ultraviolet absorption (21), prior to being separated by $12 \%$ SDS-polyacrylamide gel electrophoresis with $35 \mu \mathrm{g}$ protein loaded on each lane and transferred onto a polyvinylidene difluoride membrane (GE Healthcare Life Sciences, Chalfont, UK). Membranes were blocked with 5\% non-fat milk in Tris-buffered saline with $0.1 \%$ Tween-20 at room temperature for $2 \mathrm{~h}$. The membranes were subsequently probed with primary antibodies against TGF $\beta$ (anti-mouse; 3711S; 1:10,000; Cell Signaling Technology, Inc., Danvers, MA, USA) and $\beta$-actin (anti-mouse; 4967S; 1:10,000; Cell Signaling Technology, Inc.). Following three washes with TBST, membranes were incubated with secondary antibody (Goat anti mouse-IgG-HRP, 1:10,000, Cell Signaling Technology, Inc.). Signals were developed using an Enhanced Chemiluminescence kit (Thermo Fisher Scientific, Inc.). Immuno reactive bands were quantified individually by estimating the number of pixels in ImageJ software version 1.4.1 (National Institutes of Health, Bethesda, MD, USA).

Reverse transcription-quantitative PCR (RT-qPCR). Total RNA was extracted from cells using TRIzol ${ }^{\circledR}$ (Invitrogen; Thermo Fisher Scientific, Inc.) in accordance with the manufacturer's protocol, later tested by the following $50 \mu \mathrm{l}$

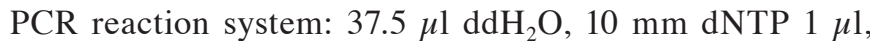
10x5 $\mu \mathrm{l}$ PCR buffer, $25 \mathrm{~mm} \mathrm{Mgcl} 23 \mu \mathrm{l}$, upstream primer $1 \mu \mathrm{l}$, downstream primers $1 \mu \mathrm{l}$, template cDNA $1 \mu \mathrm{l}\left(100^{\circ} \mathrm{C}\right.$ water bath for $1 \mathrm{~min}, 0.5 \mu \mathrm{l}$ Tag enzymes added over ice then $50 \mu$ l liquid paraffin added followed by centrifugation at $11,180 \mathrm{x} \mathrm{g}$ at $4^{\circ} \mathrm{C}$ for $1 \mathrm{~min}$. PCR conditions were: $94^{\circ} \mathrm{C}$ $1 \mathrm{~min}, 58^{\circ} \mathrm{C} 50 \mathrm{sec}, 72^{\circ} \mathrm{C} 90 \mathrm{sec}, 40$ cycles and then $72^{\circ} \mathrm{C}$ for $10 \mathrm{~min}$, followed by storage at $-20^{\circ} \mathrm{C}$. RNAs were then reverse transcribed using the PrimeScript ${ }^{\mathrm{TM}}$ RT-PCR kit (Takara Biotechnology Co., Ltd., Dalian, China). qPCR was performed on the resultant cDNA using the $\mathrm{SYBR}^{\circledR}$ Green Master mix (Takara Biotechnology Co., Ltd.) to determine the expression of miR-125a. PCR-master mix (45 $\mu \mathrm{l})$ containing $2 \mu \mathrm{l}$ of enzyme-mix from the Qiagen OneStep RT-PCR kit (including the RT and the hot-start Taq polymerase), 1X RT-PCR buffer (included in kit) $400 \mu \mathrm{M}$ of each dNTP, 20U of Riblock RNase Inhibitor (Fermentas; Thermo Fisher Scientific, Inc.) and $200 \mathrm{nM}$ of each forward and reverse primer was added to $5 \mu \mathrm{l}$ of previously treated sample RNA. The initial steps of the cycle program consisted of $30 \mathrm{~min}$ at $50^{\circ} \mathrm{C}$ to produce enough specific initial DNA and $15 \mathrm{~min}$ at $95^{\circ} \mathrm{C}$ for the activation of the Taq polymerase. Overall, 40 cycles of $15 \mathrm{sec}$ at $95^{\circ} \mathrm{C}$, $30 \mathrm{sec}$ at $58^{\circ} \mathrm{C}$ and $1 \mathrm{~min}$ at $72^{\circ} \mathrm{C}$ were performed. Following a final elongation step at $72^{\circ} \mathrm{C}$ for $10 \mathrm{~min}$, the amplification product was cooled at $8^{\circ} \mathrm{C}$. The following primers were used (Sangon Biotech Co., Ltd.): Forward, 5'-CGATGTCGTATA TGCGTCGTATG-3' and reverse, 5'-CGTAGTCGTCGT ATGCTAGCGT-3' for miR-125a; forward, 5'-CGTAGCTAG TCGTATGCTGA-3' and reverse, 5'-CGATGTCGTAGGTCT AGCTGATGC-3' for TGF $\beta$. U6 forward, 5'-ATGACACGC AAATTCCCTCGAGGCGTGAAGCGTTCCATA-3' and reverse, 5'-TATGGAACGCTTCACGCCTCGAGGGAATTT GCGTGTCAT-3' small nuclear RNA served as an internal control for miRNA and glyceraldehyde 3-phosphate dehydrogenase $(G A P D H)$ forward, 5'-GCACCGTCAAGGCTG AGAAC-3' and reverse, 5'-TGGTGAACGCCAGTGGA-3' for mRNA. Data was normalized to $U 6$ and $G A P D H$ using the $2^{-\triangle \Delta \mathrm{Cq}}$ method (22).

Statistical analysis. The relative expression of miRNA in each target was expressed (mean \pm standard deviation/standard error of the mean), and the difference expression of miRNA between different groups was compared with non-paired test or single factor variance analysis. The Hardy-Weinberg equilibrium was tested using the Pearson's Chi-square test (goodness-of-fit) for the SNP. Genotype distribution differences between cohorts were examined using the Pearson's $\chi^{2}$ test and logistic regression analysis. All statistical analyses were two-sided and were performed in SPSS software version 17.0 (SPSS, Inc., Chicago, IL, USA). $\mathrm{P}<0.05$ was considered to indicate a statistically significant difference. The experiments were repeated three times.

\section{Results}

TGF $\beta$ is a target of $m i R-125 a$. Based on reports that TGF $\beta$ was functionally involved in the development of pneumonitis in patients with lung cancer that received radiotherapy, and that miR-125a negatively regulates $T G F \beta$, the present study aimed to investigate the molecular mechanism underlying 


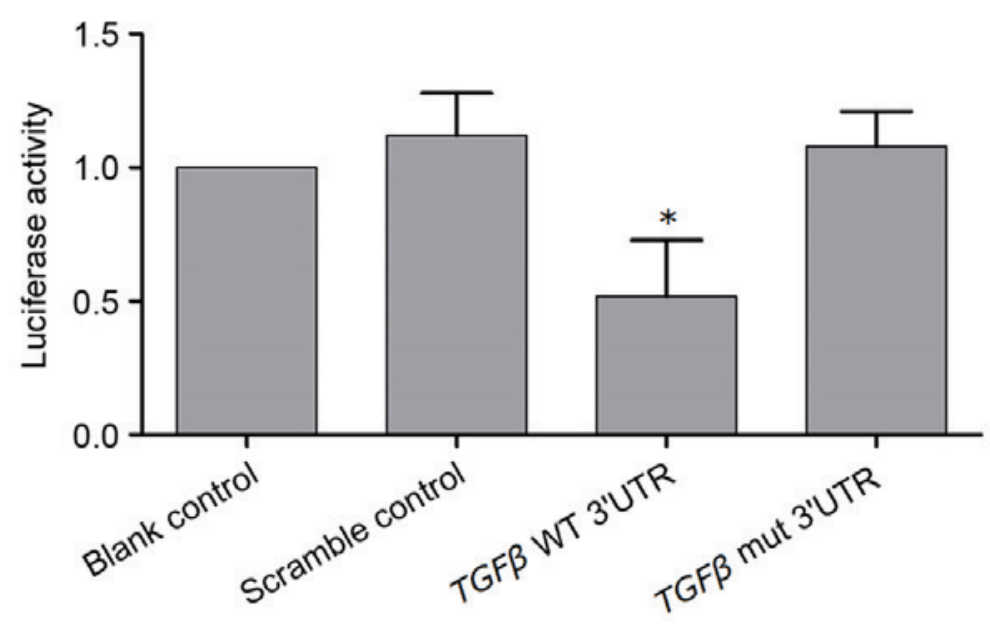

Figure 2. TGF $\beta$ was verified as a direct target gene of miR-125a by dual-luciferase activity reporter assay. The relative luciferase activity of miR-125a-overexpressing lung cancer cells transfected with wild-type $T G F \beta$ 3'UTR constructs was significantly reduced compared with blank/scramble controls, whereas cells transfected with mutant $T G F \beta 3$ 'UTR constructs exhibited comparable levels, indicating $T G F \beta$ gene as a direct target of miR-125a (mean \pm standard deviation). ${ }^{*} \mathrm{P}<0.01$, as compared with the blank controls. $T G F \beta$, transforming growth factor $\beta$; miR, microRNA; UTR, untranslated region; WT, wild-type; mut, mutant.

pneumonitis, a primary adverse effect of radio therapy in the treatment of lung cancer, including the downstream mediators and signaling pathways of miR-125a. Online miRNA target prediction tools (http://www.targetscan.org) were used to search the target gene of miR-125a; these identified $T G F \beta$ as a candidate target gene in lung cancer cells with the 'seed sequence' (390-397 bp) in the 3'UTR of TGF 3 (Fig. 1).

To verify $T G F \beta$ as a direct target gene of miR-125a, a dual-luciferase activity reporter assay was performed on miR-125a-overexpressing lung cancer cells transfected with wild-type $T G F \beta$ 3'UTR constructs or mutant $T G F \beta$ 3'UTR constructs. As presented in Fig. 2, compared with the scramble controls, cells transfected with wild-type $T G F \beta$ 3'UTR constructs exhibited reduced relative luciferase activity $(\mathrm{P}<0.05)$, whereas cells transfected with mutant TGF 3 3'UTR constructs demonstrated comparable luciferase activity ( $\mathrm{P}>0.05$ ), indicating that $T G F \beta$ was a direct target of miR-125a and that the binding site is located at 390-397 bp of the 3'UTR of $T G F \beta$.

Effects of rs 12976445 on miR-125a expression. Due to the negative regulatory association between miR-125a and TGF $\beta$, the effect of the rs12976445 polymorphism on the interaction between miR-125a and TGF $\beta$ was investigated. C-509T is located $509 \mathrm{bp}$ upstream of the exon1 codon of the gene. Tissue samples were collected from patients with lung cancer and genotyped as CC $(n=36)$, CT $(n=18)$ or TT $(n=6)$. The miR-125a expression levels of the three genotypes were then analyzed. As presented in Fig. 3, the expression levels of miR-125a were significantly greater in the CC genotype group compared with the genotype groups carrying the minor allele, the $\mathrm{CT}$ and TT groups $(\mathrm{P}<0.05)$. These two groups exhibited comparable miR-125a expression levels, suggesting that the presence of the minor allele, $\mathrm{T}$ compromised the expression of miR-125a.

To investigate the association between the rs12976445 polymorphism and the risk of pneumonitis in patients with lung cancer that received radio therapy, 534 lung cancer patients with diagnosed pneumonitis and 489 lung cancer

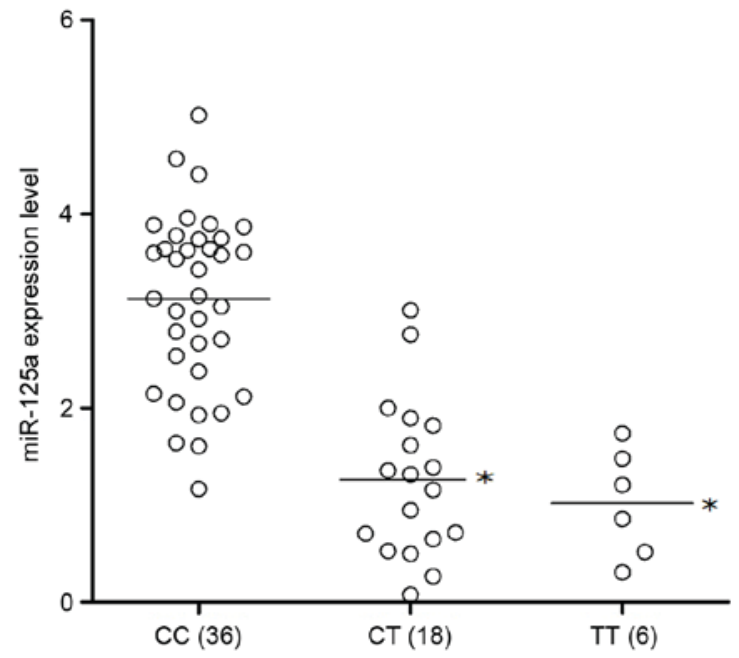

Figure 3. Expression levels of miR-125a in tissue samples from patients with lung cancer. miR-125a expression levels of samples carrying the minor allele $(\mathrm{T})$, the CT $(\mathrm{n}=18)$ and TT $(\mathrm{n}=8)$ genotypes, were decreased compared with samples genotyped as $\mathrm{CC}(\mathrm{n}=36)$, suggesting that the presence of the minor allele of the rs12976445 polymorphism compromised the expression of miR-125a. ${ }^{*} \mathrm{P}<0.01$, as compared with the $\mathrm{CC}$ genotype group. $\mathrm{miR}$, microRNA.

patients without pneumonitis were enrolled in the present study. The distributions of the rs12976445 polymorphism were in Hardy-Weinberg equilibrium among the case group and controls. As the expression levels of miR-125a were similar in the TT and CT groups, and significantly reduced compared with the CC group, a dominant model of the minor allele was indicated. Since the frequency of TT was relatively low in the population assessed, the CT and TT groups were combined. Significant differences were observed regarding genotype distribution of rs12976445 between patients with and without pneumonitis [odds ratio $(\mathrm{OR})=1.43 ; 95 \%$ confidence interval $(\mathrm{CI})=1.13-1.94 ; \mathrm{P}=0.03]$, as presented in Table II. This is despite the fact that the polymorphism is not located in the binding site of miR-125a in the 3'UTR of $T G F \beta$, and the effect of the polymorphism on the interaction between 
Table II. miR-125a genotype distribution in lung cancer patients with and without pneumonitis.

\begin{tabular}{lccc}
\hline Genotype $(+)(\mathrm{n}=534)(\%)$ & $\begin{array}{c}\text { Pneumonitis } \\
(-)(\mathrm{n}=489)(\%)\end{array}$ & $\begin{array}{c}\text { Adjusted OR } \\
(95 \% \mathrm{CI})\end{array}$ \\
\hline CC & $363(67.97)$ & $361(73.82)$ & \\
CT & $160(29.96)$ & $122(24.95)$ & \\
TT & $11(2.07)$ & $6(1.23)$ & \\
CT/TT & $171(32.03)$ & $128(26.18)$ & $1.43(1.13-1.94)$ \\
& & & $\mathrm{P}=0.03$ \\
\hline
\end{tabular}

OR, odds ratio; CI, confidence interval.

miR-125a and $T G F \beta$ may therefore be attributed to an alteration in the secondary structure caused by the presence of the minor allele, or linkage disequilibrium with another variant that may directly cause the disruption between miR-125a and $T G F \beta$. Alternatively, the polymorphism may compromise the transcription of $T G F \beta$.

RT-qPCR and western blot analyses were performed to investigate the mRNA and protein expression levels of TGF $\beta$ in each rs12976445 polymorphism genotype group. As presented in Fig. 4, the mRNA and protein expression levels of TGF $\beta$ were reduced in the CC genotype group, compared with the minor-allele-carrying CT/TT genotype groups $(\mathrm{P}<0.05)$, which had decreased expression levels of miR-125a. These findings further support the hypothesis of the negative association between miR-125a and TGF $\beta$.

To investigate the interaction between miR-125a and $T G F \beta$, the mRNA and protein expression levels of TGF $\beta$ in A549 cells transfected with $T G F \beta$ siRNA, an miR-125a mimic, and anti-miR-125a were analyzed and compared with the scramble controls. TGF $\beta$ protein expression levels were reduced in cells transfected with an miR-125a mimic or TGF $\beta$ siRNA, compared with the scramble control (Fig. 5A). TGF $\beta$ protein expression levels were greater in cells transfected with anti-miR-125a, compared with the scramble control (Fig. 5B). A similar pattern was observed in $T G F \beta$ mRNA expression levels $(\mathrm{P}<0.05$; Fig. $5 \mathrm{C}$ and $\mathrm{D})$. The above findings further validate the negative association between miR-125a and its target $T G F \beta$.

\section{Discussion}

A common complication of lung radio therapy, radiation-induced lung injury, including radiation fibrosis and pneumonitis, is associated with a poor prognosis. Radio therapy-induced pneumonitis may be predicted by pulmonary function parameters in the clinic (23). The infiltration of inflammatory cells into alveolar spaces and the pulmonary interstitium is a characteristic of pneumonitis at the cellular level. In the present study, bioinformatics tools were used to identify potential binding sites of miR-125a in the 3'UTR of $T G F \beta$, and this was subsequently confirmed using a dual-luciferase reporter system. In addition, tissue samples were collected from patients with lung cancer and genotyped as CC $(n=36)$, CT $(n=28)$ or TT $(n=6)$. The expression levels of
miR-125a and $T G F \beta$ were determined in these samples, which exhibited upregulated miR-125a and downregulated TGF $\beta$ protein and mRNA expression levels in cells genotyped as CC compared with cells carrying the minor allele, $\mathrm{T}$.

It has previously been demonstrated that cytokines are involved in the development of pneumonitis (24). TGF $\beta$ is involved in the pathogenesis of radiation-induced pneumonitis; therefore, the outcomes of patients with radiation-induced pneumonitis may be predicted by $T G F \beta$ expression. As a ubiquitous profibrotic and immunomodulatory cytokine, $T G F \beta$ is essential in tissue responses to irradiation. It has been observed that rising plasma levels of $T G F \beta 1$ during thoracic radio therapy is associated with the subsequent occurrence of radiation-induced pneumonitis (25-27). As a result, TGF $\beta$ has been adopted as a sensitive plasma marker of radiation-induced pneumonitis following thoracic irradiation. A previous animal study demonstrated that anti-TGF $\beta$ antibodies decreased the levels of $T G F \beta$ during thoracic irradiation, resulting in attenuation of radiation-induced pneumonitis (28). In the present study, miR-125a was identified as a regulator of $T G F \beta$ in A549 cells using in silico analysis and a dual-luciferase reporter system.

Previous studies have demonstrated that the C-509T SNP is associated with $T G F \beta$ gene promoter activity enhancement, and the $\mathrm{T}$ allele of $\mathrm{C}-509 \mathrm{~T}$ is associated with increased serum levels of $T G F \beta$. The serum level of $T G F \beta$ in the CC genotype is decreased compared with the CT or TT genotypes (29). In addition, a previous study revealed that greater circulating $T G F \beta$ levels during radiation therapy are correlated with poor prognosis of locally advanced NSCLC (30). Therefore, compared with those with TGF $\beta$ C-509T CT or TT genotypes, patients with CC genotype may have improved survival due to reduced circulating $T G F \beta$ levels during radio therapy. Furthermore, various studies have implicated $T G F \beta$ in radiation-induced lung injury; in particular, a persistently elevated or rising level of $T G F \beta$ during the course of thoracic radiation therapy has been associated with symptomatic radiation pneumonitis $(14,27)$. Since miR-125a was identified as a regulator of $T G F \beta$ and rs12976445 interferes with the mature processing of this miRNA, reducing the miRNA expression levels, the present study examined the effect of rs12976445 on the expression levels of miR-125a and TGF $\beta$. The expression levels of miR-125a were markedly greater in the $\mathrm{CC}$ genotype group compared with those carrying the minor allele, the CT and TT groups, which exhibited comparable miR-125a expression levels, indicating that the $\mathrm{T}$ allele is dominant.

The MIR125A gene, which encodes miR-125a, is situated in a gene cluster on chromo some 19q13.41. miR-125a has been reported to be involved in the pathogenesis of human diseases, including verrucous carcinoma (31), ovarian cancer (32), gastric cancer (33), breast cancer (34) and systemic lupus erythematosus (35). It has previously been demonstrated that an SNP (rs12976445) in the precursor of miR-125a, located in the stem loop of the molecule, may undermine the mature processing of the miRNA, leading to a decrease in the production of miR-125a (21). In the present study, 534 lung cancer patients with diagnosed pneumonitis and 489 lung cancer patients without pneumonitis were recruited, and significant differences were noted regarding genotype distribution of 

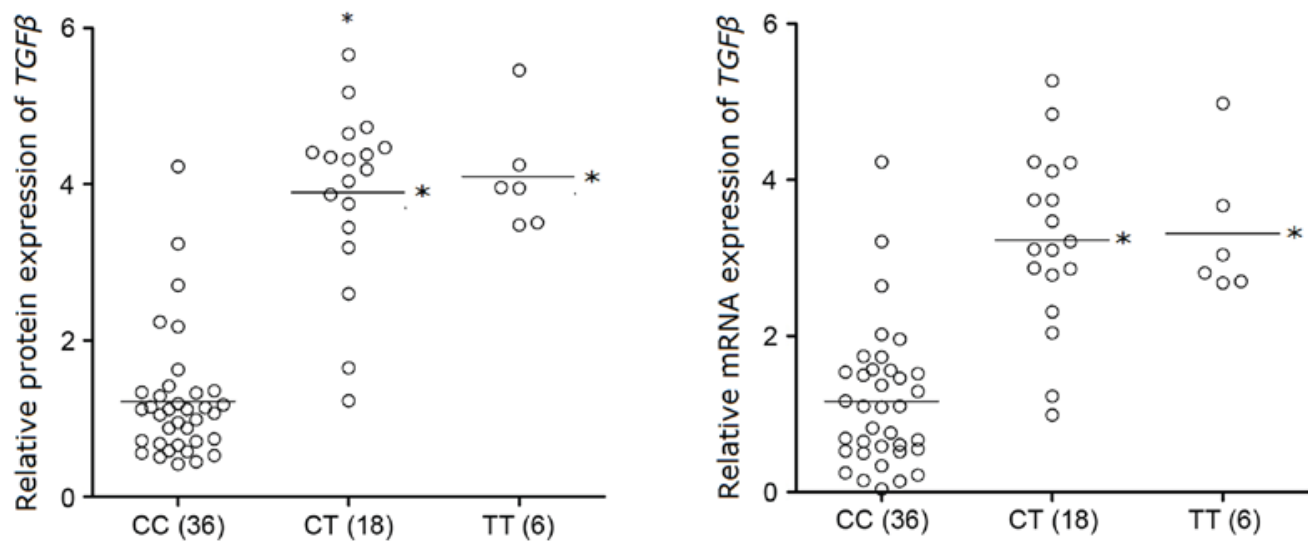

Figure 4. Protein and mRNA expression levels of TGF $\beta$ in the three genotype groups. TGF $\beta$ protein and mRNA expression levels in the CC genotype group were reduced compared with the CT/TT genotype groups, validating the negative association between miR-125a and $T G F \beta$. " $\mathrm{P}<0.01$, as compared with the CC genotype group. $T G F \beta$, transforming growth factor $\beta$; miR, microRNA.

A

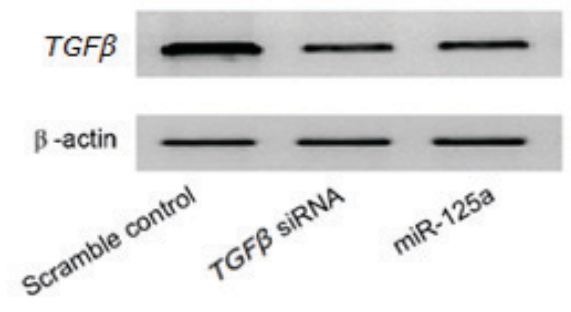

C

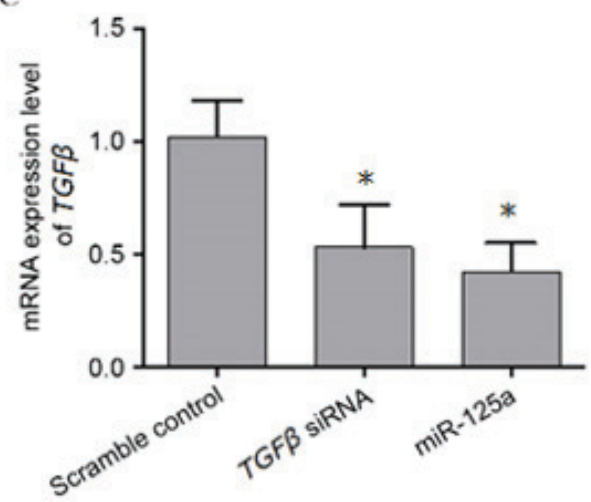

B

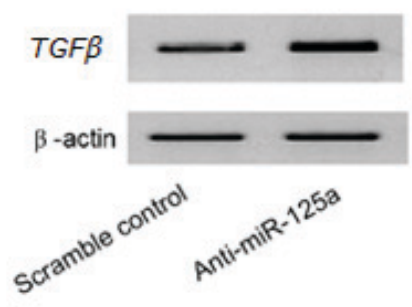

D

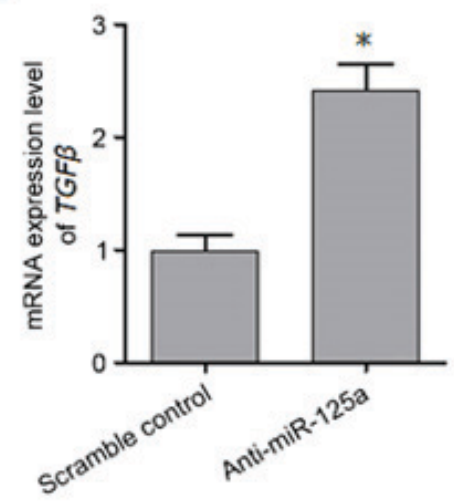

Figure 5. Protein and mRNA expression levels of TGF $\beta$ in A549 cells transfected with TGF $\beta$ siRNA, an miR-125a mimic oranti-miR-125a compared with the scramble control. (A) TGF $\beta$ protein expression levels were reduced in cells transfected with an miR-125a mimic or TGF $\beta$ siRNA, compared with the scramble control. (B) TGF $\beta$ protein expression levels were increased in cells transfected with anti-miR-125a compared with the scramble control. Similar patterns were observed in mRNA expression levels following transfection with (C) anmiR-125a mimic or TGF $\beta$ siRNA and (D) anti-miR-125a. These findings further validated the negative association between miR-125a and its target $T G F \beta .{ }^{*} \mathrm{P}<0.01$, as compared with the scramble controls. TGF $\beta$, transforming growth factor $\beta$; siRNA, small interfering RNA; miR, microRNA.

rs12976445 between those with and without pneumonitis $(\mathrm{OR}=1.43 ; 95 \% \mathrm{CI}=1.13-1.94 ; \mathrm{P}=0.03)$.

In conclusion, the results of the present study demonstrated that patients with radiation-induced pneumonitis have decreased expression levels of miR-125a in lung tissue. Presence of the minor allele of the rs12976445 polymorphism increased expression levels of $T G F \beta$ by decreasing the expression levels of miR-125a, and therefore may be associated with the development of pneumonitis in patients with lung cancer receiving radio therapy. These results suggested that rs12976445 may be a potential biomarker to predict the risk of pneumonitis following radio therapy.

\section{Acknowledgements}

Not applicable.

\section{Funding}

No funding was received. 


\section{Availability of data and materials}

The datasets used and/or analyzed during the current study are available from the corresponding author on reasonable request.

\section{Authors' contributions}

H-YQ planned the study, collected and interpreted the data, assembled the literature and wrote the manuscript. TY collected and interpreted the data, and wrote the manuscript. $\mathrm{J}-\mathrm{FH}$ interpreted the data, assembled the literature and approved the final manuscript.

\section{Ethics approval and consent to participate}

The present study was conducted according to the Declaration of Helsinki guidelines and the study protocol was approved by the Human Ethics Committee of Shaanxi Friendship Hospital.

\section{Patient consent for publication}

Written informed consent was obtained from all participants prior to the study.

\section{Competing interests}

The authors declare that they have no competing interests.

\section{References}

1. Midanik LT, Klatsky AL and Armstrong MA: Changes in drinking behavior: Demographic, psychosocial, and biomedical factors. Int J Addict 25: 599-619, 1990.

2. Zhang WC, Shyh-Chang N, Yang H, Rai A, Umashankar S, Ma S, Soh BS, Sun LL, Tai BC, Nga ME, et al: Glycine decarboxylase activity drives non-small cell lung cancer tumor-initiating cells and tumorigenesis. Cell 148: 259-272, 2012.

3. Guan X, Yin M, Wei Q, Zhao H, Liu Z, Wang LE, Yuan X, O'Reilly MS, Komaki R and Liao Z: Genotypes and haplotypes of the VEGF gene and survival in locally advanced non-small cell lung cancer patients treated with chemoradiotherapy. BMC Cancer 10: 431, 2010.

4. Yin M, Liao Z, Yuan X, Guan X, O'Reilly MS, Welsh J, Wang LE and Wei Q: Polymorphisms of the vascular endothelial growth factor gene and severe radiation pneumonitis in non-small cell lung cancer patients treated with definitive radiotherapy. Cancer Sci 103: 945-950, 2012.

5. Hildebrandt MA, Komaki R, Liao Z, Gu J, Chang JY, Ye Y, Lu C, Stewart DJ, Minna JD, Roth JA, et al: Genetic variants in inflammation-related genes are associated with radiation-induced toxicity following treatment for non-small cell lung cancer. PLoS One 5: e12402, 2010.

6. Vlasova MA and Moshkovskii SA: Molecular interactions of acute phase serum amyloid A: Possible involvement in carcinogenesis. Biochemistry (Mosc) 71: 1051-1059, 2006.

7. Zhao L, West BT, Hayman JA, Lyons S, Cease K and Kong FM: High radiation dose may reduce the negative effect of large gross tumor volume in patients with medically inoperable early-stage non-small cell lung cancer. Int J Radiat Oncol Biol Phys 68: 103-110, 2007.

8. Rübe CE, Wilfert F, Uthe D, König J, Liu L, Schuck A, Willich N, Remberger K and Rübe C: Increased expression of pro-inflammatory cytokines as a cause of lung toxicity after combined treatment with gemcitabine and thoracic irradiation. Radiother Oncol 72: 231-241, 2004.

9. Kong FM, Ao X, Wang L and Lawrence TS: The use of blood biomarkers to predict radiation lung toxicity: A potential strategy to individualize thoracic radiation therapy. Cancer Control 15 : 140-150, 2008.
10. Fosslien E: Cancer morphogenesis: Role of mitochondrial failure. Ann Clin Lab Sci 38: 307-329, 2008.

11. Anscher MS, Kong FM, Marks LB, Bentel GC and Jirtle RL: Changes in plasma transforming growth factor beta during radiotherapy and the risk of symptomatic radiation-induced pneumonitis. Int J Radiat Oncol Biol Phys 37: 253-258, 1997.

12. Burger A, Löffler H, Bamberg M and Rodemann HP: Molecular and cellular basis of radiation fibrosis. Int J Radiat Biol 73: 401-408, 1998.

13. Hakenjos L, Bamberg M and Rodemann HP: TGF-beta1-mediated alterations of rat lung fibroblast differentiation resulting in the radiation-induced fibrotic phenotype. Int J Radiat Biol 76: 503-509, 2000.

14. Zhao L, Wang L, Ji W, Wang X, Zhu X, Hayman JA, Kalemkerian GP, Yang W, Brenner D, Lawrence TS and Kong FM: Elevation of plasma TGF-betal during radiation therapy predicts radiation-induced lung toxicity in patients with non-small-cell lung cancer: A combined analysis from Beijing and Michigan. Int J Radiat Oncol Biol Phys 74: 1385-1390, 2009.

15. Xue J, Li X, Lu Y, Gan L, Zhou L, Wang Y, Lan J, Liu S, Sun L, Jia L, et al: Gene-modified mesenchymal stem cells protect against radiation-induced lung injury. Mol Ther 21: 456-465, 2013.

16. Martin M, Lefaix $\mathrm{J}$ and Delanian S: TGF-betal and radiation fibrosis: A master switch and a specific therapeutic target? Int J Radiat Oncol Biol Phys 47: 277-290, 2000.

17. Bartel DP: MicroRNAs: Genomics, biogenesis, mechanism, and function. Cell 116: 281-297, 2004.

18. Mendell JT: MicroRNAs: Critical regulators of development, cellular physiology and malignancy. Cell Cycle 4: 1179-1184, 2005.

19. Ambros V: The functions of animal microRNAs. Nature 431: 350-355, 2004.

20. Lehmann TP, Korski K, Ibbs M, Zawierucha P, Grodecka-Gazdecka S and Jagodziński PP: rs12976445 variant in the pri-miR-125a correlates with a lower level of hsa-miR-125a and ERBB2 overexpression in breast cancer patients. Oncol Lett 5: 569-573, 2013.

21. Beaven GH and Holida ER: Ultraviolet absorption spectra of proteins and amino acids. Adv Prot Chem 7: 319-386, 1952.

22. Livak KJ and Schmittgen TD: Analysis of relative gene expression data using real-time quantitative PCR and the 2(-Delta Delta C(T) method. Methods 25: 402-408, 2001.

23. Kocak Z, Borst GR, Zeng J, Zhou S, Hollis DR, Zhang J, Evans ES, Folz RJ, Wong T, Kahn D, et al: Prospective assessment of dosimetric/physiologic-based models for predicting radiation pneumonitis. Int J Radiat Oncol Biol Phys 67: 178-186, 2007.

24. Tsoutsou PG and Koukourakis MI: Radiation pneumonitis and fibrosis: Mechanisms underlying its pathogenesis and implications for future research. Int J Radiat Oncol Biol Phys 66: 1281-1293, 2006

25. Chen Y, Williams J, Ding I, Hernady E, Liu W, Smudzin T, Finkelstein JN, Rubin P and Okunieff P: Radiation pneumonitis and early circulatory cytokine markers. Semin Radiat Oncol 12 (1 Suppl 1): S26-S33, 2002.

26. Evans ES, Kocak Z, Zhou SM, Kahn DA, Huang H, Hollis DR, Light KL, Anscher MS and Marks LB: Does transforming growth factor-beta1 predict for radiation-induced pneumonitis in patients treated for lung cancer? Cytokine 35: 186-192, 2006.

27. Fu XL, Huang H, Bentel G, Clough R, Jirtle RL, Kong FM, Marks LB and Anscher MS: Predicting the risk of symptomatic radiation-induced lung injury using both the physical and biologic parameters $\mathrm{V}(30)$ and transforming growth factor beta. Int J Radiat Oncol Biol Phys 50: 899-908, 2001.

28. Anscher MS, Thrasher B, Rabbani Z, Teicher B and Vujaskovic Z: Antitransforming growth factor-beta antibody $1 \mathrm{D} 11$ ameliorates normal tissue damage caused by high-dose radiation. Int J Radiat Oncol Biol Phys 65: 876-881, 2006.

29. Grainger DJ, Heathcote K, Chiano M, Snieder H, Kemp PR, Metcalfe JC, Carter ND and Spector TD: Genetic control of the circulating concentration of transforming growth factor type beta1. Hum Mol Genet 8: 93-97, 1999.

30. Zhao L, Ji W, Zhang L, Ou G, Feng Q, Zhou Z, Lei M, Yang W and Wang L: Changes of circulating transforming growth factor-betal level during radiation therapy are correlated with the prognosis of locally advanced non-small cell lung cancer. J Thorac Oncol 5: 521-525, 2010. 
31. Odar K, Boštjančič E, Gale N, Glavač D and Zidar N: Differential expression of microRNAs miR-21, miR-31, miR-203, miR-125a-5p and miR-125b and proteins PTEN and p63 in verrucous carcinoma of the head and neck. Histopathology 61: 257-265, 2012

32. Cowden Dahl KD, Dahl R, Kruichak JN and Hudson LG: The epidermal growth factor receptor responsive miR-125a represses mesenchymal morphology in ovarian cancer cells. Neoplasia 11: 1208-1215, 2009.

33. Nishida N, Mimori K, Fabbri M, Yokobori T, Sudo T, Tanaka F, Shibata K, Ishii H, Doki Y and Mori M: MicroRNA-125a-5p is an independent prognostic factor in gastric cancer and inhibits the proliferation of human gastric cancer cells in combination with trastuzumab. Clin Cancer Res 17: 2725-2733, 2011.
34. Iorio MV, Ferracin M, Liu CG, Veronese A, Spizzo R, Sabbioni S, Magri E, Pedriali M, Fabbri M, Campiglio M, et al: MicroRNA gene expression deregulation in human breast cancer. Cancer Res 65: 7065-7070, 2005.

35. Zhao X, Tang Y, Qu B, Cui H, Wang S, Wang L, Luo X, Huang X, Li J, Chen S and Shen N: MicroRNA-125a contributes to elevated inflammatory chemokine RANTES levels via targeting KLF13 in systemic lupus erythematosus. Arthritis Rheum 62: 3425-3435, 2010 . 